\title{
TURISMO COMO POTENCIAL PARA PROMOÇÃO DO DESENVOLVIMENTO LOCAL SUSTENTÁVEL NO ATALAIA, EM SALINÓPOLIS/PA
}

\author{
Hully Cordovil Ribon* \\ Isabelle Cristina Moraes de Souza** \\ Ismael Matos da Silva**** \\ Greicy Kelly Pfeiff*****
}

\begin{abstract}
Resumo
O turismo vem se consolidando como importante atividade geradora de renda, principalmente em municípios costeiros (a exemplo de Salinópolis), que se tornou essencial ao meio turístico no Estado do Pará. O objetivo desta pesquisa foi identificar e analisar os fatores determinantes das características naturais e da logística de infraestrutura para a dinamização do turismo na praia do Atalaia, em Salinópolis. Fez-se o cálculo de indicadores de Capacidade de Carga Turística, utilizando o método de Cifuentes (1992), o qual é constituído pela Capacidade de Carga Física (CCF), Capacidade de Carga Real (CCR) e Capacidade de Carga Efetiva (CCE). Dessa forma, obteve-se a determinação do perfil do turista que mais frequenta a praia e a capacidade máxima de visitantes se aproximou de 9.049 usuários/dia, considerando as férias. O conhecimento desse valor se torna instrumento fundamental para auxiliar a gestão da área e incentivar a atividade turística de qualidade com infraestrutura adequada nessa região.
\end{abstract}

Palavras-chave: Comunidade Local. Praia do Atalaia. Capacidade de Carga Turística. Turismo.

\footnotetext{
* Graduada em Engenharia Ambiental pela Universidade do Estado do Pará (UEPA). E-mail: hullyribon@ live.com

** Graduada em Engenharia Ambiental pela Universidade do Estado do Pará (UEPA).E-mail: souzaisabelle8@ gmail.com

**** Doutor em Ciências Agrárias pela Universidade Federal Rural da Amazônia (UFRA), professor Adjunto II da Universidade do Estado do Pará (UEPA). E-mail: imds21@yahoo.com

**** Graduada em Engenharia Ambiental pela Universidade do Estado do Pará (UEPA). E-mail: greicypfeiff@ gmail.com
} 


\section{Introdução}

O turismo, ao ser considerado como atividade econômica, desenvolve-se cooperando para o aumento de desequilíbrios socioespaciais de todas as formas. No plano geográfico, observam-se impactos referentes às transformações do território com repercussões socioantropológicas para as comunidades e sociedades. Nos países periféricos, a atividade turística produz "ilhas de prosperidade" em conflito com espaços marginais, contribuindo para a ampliação de diferentes contradições, especialmente de ordem social, cultural e econômica (CORREAA; PIMENTA, ARNDT 2009).

Segundo Teles (2006), o turismo como atividade econômica pode ser potencializado por meio de construção de vias e rodovias, ampliação da malha urbana, investimentos em infraestrutura urbana e melhoria no fornecimento de bens e serviços, contribuindo para a permanência dos visitantes. Portanto, o crescimento de alguns setores, tais como hospedagens, alimentos, bebidas e transportes, junto à formação de uma classe consumidora de produtos turísticos, dá origem a diferentes fluxos, o que resulta em uma nova ordem no processo de ocupação do espaço, percebendo-se que cada vez há menos territórios sem turistas.

O município litorâneo de Salinópolis sofreu grande expansão e desenvolvimento no setor da atividade turística; todavia, carecendo de infraestrutura necessária que beneficiasse efetivamente todos os agentes sociais envolvidos. Conforme a Secretaria Municipal de Meio de Ambiente de Salinópolis (SEMMA), seus aspectos naturais atraíram cerca de 300.000 turistas na estação do verão do ano de 2015 (SALINÓPOLIS, 2015). Assim, a necessidade de mais investimentos para o aperfeiçoamento da logística voltada para o turismo fez do município um espaço promissor para atividades vinculadas ao uso sustentável do meio ambiente e ao desenvolvimento local.

No sentido de tornar possível o avanço do atual contexto do setor turístico no Município de Salinópolis, 
transformando-o no verdadeiro espaço de oferta de atrativos turísticos de qualidade a seus visitantes e contribuindo para o desenvolvimento local da população, sob os pontos de vista ambiental, social e econômico, foi que se estruturou este estudo.

O objetivo geral da proposta foi identificar e analisar os fatores determinantes das características naturais e da logística de infraestrutura para a dinamização do turismo no Atalaia, criando oportunidades potenciais de redução das desigualdades sociais, minimização dos impactos ambientais e desenvolvimento econômico local por meio do turismo sustentável, no município de Salinópolis, no Estado do Pará.

\section{Revisão de literatura}

Segundo Firmino (2006), a formação de pesquisas no campo do turismo é recente e tem requerido embasamento multidisciplinar e interdisciplinar, voltado à compreensão dos aspectos dialéticos e conflitantes da vida turística. Enquadrado no campo das Ciências Sociais, o turismo suscita diversidade de ângulos de pesquisa cada vez mais ampla e consistente. Averigua-se literatura diferenciada no que concerne ao tema, principalmente sobre as interfaces do turismo ambiental, promovendo reflexão quanto às migrações estimuladas pela atividade, aos impactos socioambientais e às políticas públicas de desenvolvimento.

Para Corrêa, Pimenta e Arndt (2009), a atividade do turismo é historicamente incorporada às formas de produção do trabalho industrial, comercial e financeiro, nos diversos mercados internacionais. Dentro dos paradigmas modernos, o turismo se converteu e se fragmentou, transformando-se de lazer para as elites a uma atividade explorada por outras camadas sociais. Foi modificado em mercadoria barata, invenção da sociedade de consumo, e transfigurou-se, revelando, pelos significados e pelos dilemas, a complexidade das sociedades contemporâneas.

Para a Organización Mundial del Turismo (2001), a proteção do meio ambiente e dos recursos naturais deve ser 
realizada por todos os agentes do desenvolvimento turístico,com a finalidade de crescimento econômico estruturado, constante e sustentável que seja capaz de satisfazer igualitariamente os anseios e aspirações das gerações presentes e futuras.

De acordo com o art. $2^{\circ}$ da Lei $n^{\circ} 11.771 / 2008$, que dispõe sobre a Política Nacional de Turismo (BRASIL, 2008): "Considera-se turismo as atividades realizadas por pessoas físicas durante viagens e estadas em lugares diferentes do seu entorno habitual, por período inferior a um (01) ano, com finalidade de lazer, negócios ou outras".

SegundooMinistério das RelaçõesExteriores (BRASIL, 2006), o turismo se distingue como um dos setores econômicos e sociais mais importantes do mundo, acrescentando as áreas de negócios, visita a amigos e familiares, viagens para estudos, religião, saúde, eventos esportivos, conferências e exposições, além das tradicionais viagens de férias. Esse quadro é bastante positivo para a contribuição de geração de trabalho e renda, em relação à potencial capacidade de geração de ocupação da atividade. Cerca de $6 \%$ a $8 \%$ do total de empregos gerados no mundo depende do turismo.

Corrêa, Pimenta e Arndt (2009) afirmam que no Brasil o desenvolvimento do turismo é crescente e que, devido a isso, tornou-se atividade geradora de riqueza para exportação. Contudo, à medida que há avanço econômico, sua imagem é reduzida à dimensão mercadológica. Isso é perceptível por meio dos programas governamentais, no trade turístico e nos comportamentos dos agentes empresariais.

Para Nunes (2009), as diferentes esferas governamentais têm recorrido ao turismo como estratégia para o desenvolvimento local, firmados na ideia de que a indústria turística apresenta potencial para reduzir desigualdades econômicas e sociais por meio da geração de emprego e renda. Algumas estratégias podem apresentar resultados positivos, em contraposição a outras, que podem ser desastrosas e dificilmente reversíveis.

Portuguez, Seabra e Queiroz (2012) afirmam que transformar o desenvolvimento e o turismo em benefício 
para as pessoas, significa fazer a adoção de políticas que criem oportunidades de trabalho e renda para a parte majoritária; contudo, ainda lhes dando proteção social, centralizando o homem, promovendo sua realização. Espera-se que haja atividades de revalorização do lugar e de crédito aos habitantes. Atividades planejadas localmente, iniciando-as do social e cultural às atividades econômicas, invertendo a ordem e os valores capitalistas. As propostas de desenvolvimento na escala humana, para o desenvolvimento social e o turismo de base local mudam o eixo de interesse das ações.

Dessa forma, Ruschmann (2008) alega que o turismo sustentável precisa englobar a presença de turistas mais conscientes e que, desse modo, a sua interação com as comunidades receptoras da atividade turística nos meios social, cultural e ambiental seja de maneira equilibrada e harmônica com o meio ambiente.

Santos e Kadota (2012) asseveram que o setor turístico, também conhecido como a indústria turística, gera benefícios, não somente para os envolvidos em sua cadeia produtiva, mas também para terceiros fora do mercado, por meio de seus efeitos de transbordamento. Entretanto, essas consequências podem ser benéficas (positivas) ou causarem danos (negativas).

$\mathrm{O}$ aumento da importância da atividade turística incentivou a valorização da cultura, proteção ao meio ambiente natural, aumento da conexão de transporte entre outras, sendo esses exemplos de externalidades positivas. Além disso, é considerado atividade-chave, pois é propulsora de geração de emprego e renda melhorando as condições de vida da população, desde que haja estratégias de planejamento adequadas. No entanto, entre as negativas, tem-se como: a destruição da fauna e flora, degradação da paisagem, aumento da produção de lixo e a criminalidade, devido à massificação do turismo com a transferência de multidões, veículos, ruídos e poluição para os locais de destino (SANTOS; KADOTA, 2012).

As zonas costeiras são consideradas como ecossistema de transição entre ambientes marinhos e continentais. A importância dessas áreas vem crescendo, motivando o 
aumento de atividades humanas e também de indústrias. Isso se deve ao incremento da quantidade de turistas que se destinam a estes locais, tornando a atividade turística como a principal fonte de renda da comunidade local residente nessa região (SILVA et al., 2013).

Apesar disso, os ecossistemas costeiros são os que mais sofrem com os impactos ambientais e socioeconômicos devido às atividades do setor turístico. Segundo Silva (2012), as praias são consideradas os destinos turísticos que recebem a maior quantidade de visitantes em busca de lazer e tranquilidade. Porém, apesar de trazer benefícios econômicos, o turismo é o causador do aumento da degradação desses ambientes naturais.

Segundo Teixeira e Oliveira (2015), com o crescimento das atividades turísticas em ambientes naturais, surge a necessidade de minimizar os impactos gerados pelo seu uso exagerado e a busca pela sustentabilidade. Com isso, algumas metodologias foram desenvolvidas com a finalidade da verificação da quantidade de visitantes que essas áreas suportam. Entre esses métodos, tem-se o cálculo da Capacidade de Carga Turística.

De acordo com Rocha (2011), a Capacidade de Carga (CC) é o método que visa a analisar o quanto os recursos naturais de determinada área podem resistir com o mínimo de impacto. Esse mesmo conceito, ao ser relacionado ao setor do turismo, que se considera a Capacidade de Carga Turística (CCT), pode ser caracterizada como o número de turistas que a região de destino poderá comportar visando não apenas a quantidade de pessoas mas também a infraestrutura básica para atender os mesmos.

Ruschmann, Paolucci e Maciel (2008) abordam que a maior parte dos métodos de análise de CCT para ambientes naturais - como praias, trilhas, parques, entre outros -, envolve a medida de quatro elementos, como: biofísicos, os quais estão relacionados aos recursos naturais; socioculturais, englobando os efeitos do turismo na população local; psicológico do visitante, levando-se em consideração seu número máximo do qual a área está capaz de receber; e o manejo e gestão da área, 
referindo-se ao controle do nível de visitação, infraestrutura e os recursos humanos do local de destino.

Uma das metodologias mais conhecidas para o cálculo da CCT é a que foi concebida por Cifuentes (1992), que tem por finalidade definir a quantidade máxima de pessoas que poderiam usufruir de um território em um período de tempo. O método proposto têm componentes tanto biológicos quanto sociais. Assim, a metodologia estabelece três níveis de capacidade de carga: Capacidade de Carga Física (CCF), Capacidade de Carga Real (CCR) e a Capacidade de Carga Efetiva (CCE) (CORDEIRO; LEITE; SELVA, 2013).

Conforme Zamboni e Pérez (2013), o cálculo da CCT é uma estratégia aproveitável para a redução dos impactos dos visitantes nos destinos turísticos. Portanto, com o estabelecimento de um valor a partir desse cálculo, pode ser determinado o nível de saturação do meio ambiente e o quanto esse ainda poderá suportar.

A análise de CCT de uma localidade é um dispositivo essencial como assistência para elaboração de políticas públicas, a fim de que haja melhoria na qualidade de vida da comunidade local, incentivando, também, a preservação dos recursos naturais e o bem-estar do visitante. Além disso, a participação da população na construção dessas políticas visando ao atendimento de seus interesses é necessária para o desenvolvimento local da área. Portanto, para que a atividade turística seja exercida de forma sustentável, deve ter o envolvimento de três pilares: o econômico, o social e o ambiental (ROCHA, 2011).

O estudo da CCT também é fundamental à gestão sustentável de áreas costeiras, pois, segundo a Faculdade de Ciências da Universidade de Lisboa (FCUL, 2013), identifica parâmetros quantitativos e qualitativos, os quais objetivam o usufruto de um espaço, como as praias, em que o potencial recreativo também proporcione o retorno econômico para a comunidade local e a preservação dos valores ambientais.

Para Sousa (2011), o turismo possibilita o desenvolvimento local e a melhoria da qualidade de vida da população de uma região. Logo, é essencial conhecer as 
dificuldades que são enfrentadas pelo setor de turismo e a identificação dos cenários em que poderão ser efetivados projetos estratégicos para a atividade, verificando também as condições do local.

Dessa maneira, é importante verificar o potencial de uma determinada área para o desenvolvimento das atividades turísticas de forma sustentável, sendo a execução desta pesquisa realizada por meio de ferramentas que possam mensurar o nível de sustentabilidade, como o estudo da Capacidade de Carga Turística do Atalaia, em Salinópolis/PA.

\section{Material e métodos}

A pesquisa foi realizada no município de Salinópolis, localizado na Mesorregião Nordeste do Estado do Pará, tendo como área de estudo a Praia do Atalaia (Figura 1), situada na Microrregião do Salgado. O município está situado a $220 \mathrm{~km}$ da capital, Belém, por via terrestre, cujo principal acesso se dá por meio da rodovia BR-316 e da PA-124.

Figura 1 - Praia do Atalaia

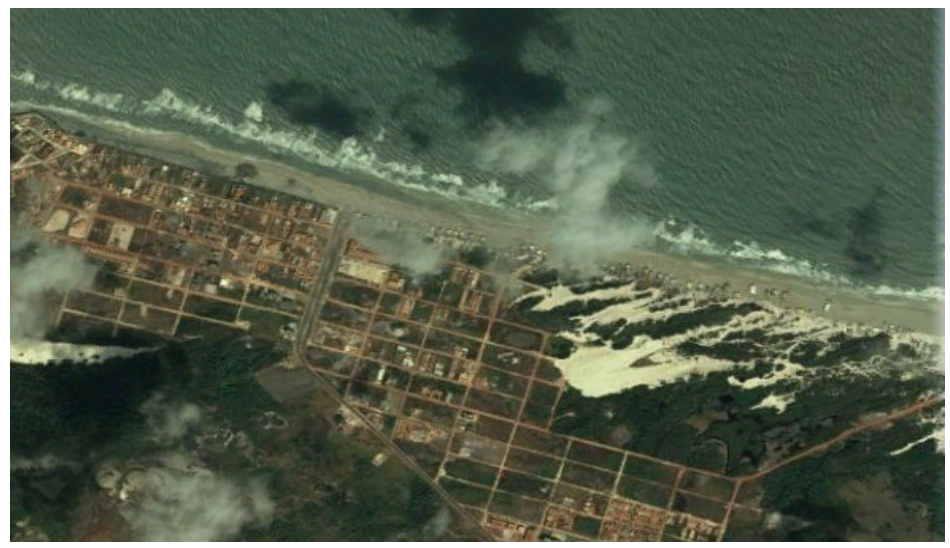

Fonte: Google Earth (2016).

Os levantamentos de dados utilizados na pesquisa foram realizados por meio de métodos qualitativo e quantitativo de origem primária, obtidos por meio de coleta de campo, a partir da: 
- compreensão e análise visual do ambiente da pesquisa;

- execução e aplicação de 225 questionários a turistas e visitantes, definidos por meio de cálculo amostral, com 30 questões sobre sua percepção acerca do local durante o mês de julho de 2016 (definido assim por ser o período do ano no qual há maior quantidade de visitantes, de acordo com dados de 2015 da Secretaria Municipal de Meio Ambiente).

- realização de duas entrevistas abertas com representantes de órgãos do governo, como a Secretaria de Turismo de Salinópolis (SETURSAL) e Secretaria Municipal de Meio Ambiente (SEMMA), e de uma entrevista estruturada com representante da comunidade local, como a Presidente dos Barraqueiros do Atalaia.

Ressalta-se que o questionário aplicado à comunidade foi constituído de perguntas diferentes daqueles aplicados aos turistas, pois se tratou especificamente de adquirir informações pertinentes sobre a comunidade moradora da região do Atalaia. E os dados secundários foram obtidos por meio de revisão de literatura em periódicos e textos acadêmicos.

A análise dos dados dos questionários foi realizada por meio de estatística descritiva univariada, com o uso do software Microsoft Office Excel 2010, visto que, de acordo com a Organização Mundial do Turismo (OMT, 2006), é essencial para o desenvolvimento de estudos no campo do turismo por permitir o conhecimento e, também, predizer aspectos fundamentais para a construção do perfil do turista.

Kirsten (2011) esclarece que a estatística univariada envolve a redução dos dados por meio do uso de medidas de tendência central (média, moda e mediana), e de dispersão (desvio-padrão, variância, valores máximo e mínimo, coeficiente de variância e de correlação). Portanto, para esta pesquisa, com o intuito de resumir as informações e as tornar mais compreensíveis, foram utilizadas medidas de tendência central.

Para o estabelecimento dos indicadores da Capacidade de Carga Turística (CCT) do território foi utilizada a 
Metodologia de Cifuentes (1992), a qual sofreu modificações de acordo com as características do local. A realização do cálculo da CCT é composta por três níveis: a Capacidade de Carga Física (CCF), Capacidade de Carga Real (CCR) e a Capacidade de Carga Efetiva (CCE). Segundo Cifuentes et al. (1999), a CCF indica o número máximo de visitas que podem ser feitas na área durante o dia; a CCR é o limite máximo dessas visitações após serem modificados por fatores de correção, os quais são estimados de acordo com as características da área de estudo; já a CCE é o resultado final considerando o valor da capacidade real do local.

Portanto, com base nessa metodologia, a CCF pode ser calculada pela seguinte equação:

$$
\mathrm{CCF}=\frac{\mathrm{S}}{\mathrm{SP}} \times \mathrm{NV}
$$

Onde:

S: Superfície disponível em metros lineares;

SP: Superfície utilizada por pessoa;

Nv: Número de vezes que o local é visitado pela mesma pessoa.

$\mathrm{E}$ esse número pode ser calculado pela equação a seguir:

$$
\mathrm{Nv}=\frac{\mathrm{Hv}}{\mathrm{Tv}}
$$

Sendo:

Hv: Horário de visita do local;

Tv: Tempo necessário para visita.

O cálculo da CCR é realizado por meio da aplicação de fatores de correção sobre a CCF. Esses fatores dependerão dos atributos locais da área de estudo. Conforme a metodologia de Cifuentes (1992), os fatores de correção dos locais submetidos ao turismo são: fator social, acessibilidade, precipitação, brilho solar, alagamento, fechamento eventual do local, entre outros.

No entanto, para o cálculo desse fator, emprega-se esta fórmula geral: 


$$
\mathrm{FC}=1-\frac{\mathrm{ML}}{\mathrm{MT}}
$$

Onde:

FC: Fator de Correção da variável;

ML: Magnitude Limitante da variável;

MT: Magnitude Total variável.

Depois do cálculo dos fatores de correção para a área, a CCR é obtida pela seguinte equação:

$$
\mathrm{CCR}=\mathrm{CCF} \times \mathrm{FC} 1 \times \mathrm{FC} 2 \times \ldots \times \mathrm{FCn}
$$

Assim:

CCF: Capacidade de Carga Física;

FC1: Fator de Correção da variável 1;

FC2: Fator de Correção da variável 2;

FCn: Fator de Correção da variável "n".

A estimativa da CCE é a última etapa desse processo metodológico, pois nos procedimentos anteriores não foram consideradas as condições operacionais relacionadas ao manejo da área. Para a obtenção da CCE é necessário o conhecimento sobre a capacidade de manejo e ordenamento da área pelo órgão gestor. Logo, é adquirida por meio da comparação da Capacidade Real com a Capacidade de Manejo (CM). Assim, a CCE é definida pela seguinte equação:

$$
\mathrm{CCE}=\mathrm{CCR} \times \frac{\mathrm{CM}}{100}
$$

Onde:

CCR: Capacidade de Carga Real;

CM: Capacidade de Man ejo.

Conforme Cifuentes (1992), a CM é definida como a soma das condições requeridas pelo gestor da área para satisfazer com qualidade as funções e os objetivos da mesma. 
De acordo com Mitraud (2003, p. 333), para o cálculo

desta variável, é necessária a realização de uma listagem contendo todos os recursos humanos, os equipamentos e a infraestrutura necessários para a efetivação da administração do território (Capacidade Adequada); após isso, a comparação dessa lista com os recursos disponíveis (Capacidade Instalada).

Dessa forma, a CM é determinada a partir da avaliação da infraestrutura de gestão da praia, como: banheiro público, acessibilidade, estacionamento, limpeza e outros aspectos. Neste estudo, tal capacidade foi fundamentada por meio da análise de indicadores demonstrados na Tabela 1 , adaptada de Silva et al. (2012).

Tabela 1 - Indicadores aplicados à qualidade de gestão da Praia do Atalaia

\begin{tabular}{lccc}
\hline Indicadores & \multicolumn{3}{c}{ Grau de Atratividade } \\
\cline { 2 - 4 } Avaliados & Baixo (1) & Médio (2) & Alto (3) \\
\hline Sanitários e banheiros públicos & Ausentes & Pouco & Adequado \\
Serviços de bares e restaurantes & Ausentes & Pouco & Adequado \\
Locais para estacionamento & Ausentes & Pouco & Adequado \\
$\begin{array}{l}\text { Facilidade para informação (guia } \\
\text { de turismo) }\end{array}$ & Ausentes & Pouco & Adequado \\
$\begin{array}{l}\text { Transporte público para a praia } \\
\text { Acessibilidade à praia }\end{array}$ & Ausentes & Pouco & Adequado \\
$\begin{array}{l}\text { Elementos e infraestruturas de } \\
\text { salva-vidas }\end{array}$ & Ausentes & Pouco & Adequada \\
Limpeza na praia (resíduos) & Ausentes & Pouco & Quantidade Adequada \\
$\begin{array}{l}\text { Saneamento básico (esgotos e } \\
\text { distribuição de água) }\end{array}$ & Ausentes & Pouco & Adequada \\
Locais para recreação & Ausentes & Pouco & Adequado \\
\hline
\end{tabular}

Fonte: Adaptado e melhorado de Silva et al. (2012).

\section{Resultados e discussão}

De acordo com a SETURSAL, anualmente há um calendário de eventos criado para a atração de turistas. Períodos de longos feriados, como Carnaval, Verão (em julho, mês de férias, quando existe maior quantidade de turistas) 
e Réveillon são os que mais atraem pessoas a Salinópolis. Afirmou-se que estes eventos são realizados entre iniciativa pública e privada. A Orla do Maçarico e a Praça Central (projetada exclusivamente para eventos) são exemplos de infraestrutura. No Atalaia, também há boates particulares para a diversão de turistas.

Posteriormente, entrevistou-se a Secretaria Municipal de Meio Ambiente de Salinópolis (SEMMA), cujos projetos são direcionados à limpeza e ao recolhimento de resíduos, conforme Figura 2. Nas barracas e nos restaurantes da Praia do Atalaia, por serem propriedades privadas, este recolhimento é realizado de forma particular pelos próprios proprietários. A Superintendência do Patrimônio da União (SPU) é o órgão ligado ao Ministério do Planejamento, Desenvolvimento e Gestão e que é também incumbido de autorizar o gerenciamento da praia, incluindo a fiscalização das barracas (que operam ilegalmente desde 2012). As Secretarias, em associação, são responsáveis pelo ordenamento do espaço do Atalaia.

A maior dificuldade enfrentada pela Secretaria para o recolhimento de resíduos da Praia se reporta principalmente aos piqueniques realizados nos dias de domingo, pois a limpeza depende do nível da maré, que é variável. Dos resíduos gerados pelas pessoas que visitam o local, a casca de coco é o que causa mais trabalho para retirada, porque, além de existir em grande quantidade, é um potencial poluidor para o meio ambiente. Somente no mês de julho, período de alta temporada, a quantidade de resíduos gerados chega a 5.000 toneladas, em comparação a 500 toneladas em outros meses do ano.

Conforme a Secretaria, a razão pela qual há tanta carência de investimento em limpeza na Praia do Atalaia é a falta de planejamento da Prefeitura de Salinópolis, que faz estudos apenas para gerir os impactos possivelmente causados pelos habitantes do município e não para receber a quantidade de turistas que frequentam o Atalaia. 
Figura 2 - Veículo da Prefeitura recolhendo resíduos na Praia do Atalaia

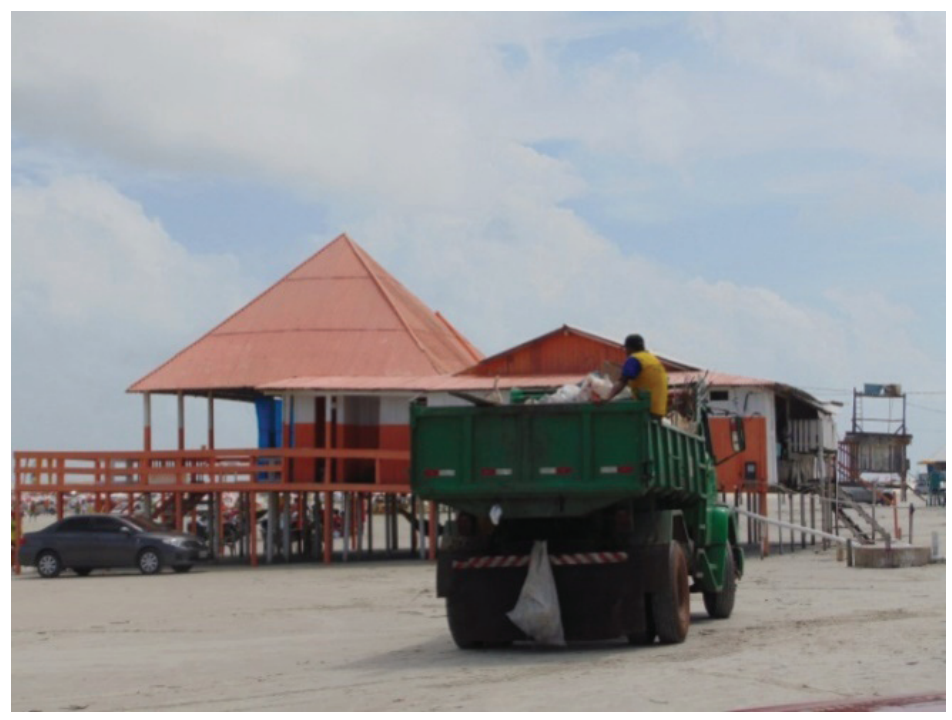

Fonte: Autores (2016).

Dos projetos sociais junto às comunidades locais, existe o "Mutirão Ecológico", que visa sensibilizar de forma ambiental crianças de escolas das redes municipal e estadual de ensino; há o a desenvolvimento de atividades lúdicas, como o Programa "Escola da Vida", que em associação com a SEMMA, é voltado para crianças e adolescentes de idades entre 8 a 16 anos. Também há oficinas de reutilização voltadas para comunidades de baixa renda e com a finalidade de agregar valor e renda para as pessoas que vivem nestas comunidades. O "Projeto Verão", chamado de "Ecoverão", propõe-se à distribuição de sacolas e ao incentivo à troca ecológica, beneficiando, assim, os atores sociais envolvidos, tanto turistas quanto órgãos institucionais e comunidade local, uma vez que cria oportunidades para redução das desigualdades e minimização dos impactos ambientais.

Outro ponto observado foi sobre o fomento à identidade cultural de Salinópolis, pouco explorado e desenvolvido. A identidade cultural é um dos principais meios de atrair pessoas com o propósito de conhecimento. Algumas atividades são 
realizadas com este fim. Dentre elas, feiras de artesanato local, nas quais há vendas de produtos criados pelas comunidades locais, gerando renda alternativa neste período.

A partir da entrevista realizada com a representante da comunidade local, foi constatado que a qualidade de vida dentro da comunidade que possui população de 3.000 pessoas na ilha é boa, referindo-se estritamente à educação, saúde e energia elétrica. No entanto, enfatizou-se a distribuição irregular e deficitária de água. Não há água encanada para a comunidade; por isso, utiliza-se água adquirida por meio da perfuração de poços subterrâneos (poço artesiano).

Com relação à existência de médicos, leitos e infraestrutura suficientes para atender a comunidade e turistas que frequentam a região, constatou-se que na Ilha do Atalaia há apenas um agente de saúde, um agente comunitário, uma enfermeira (presente a semana inteira), um médico (presente somente nos dias de quarta, quinta e sexta-feira, de $10 \mathrm{~h} 30 \mathrm{~min}$ às 12h) e dois postos de saúde. Existe um hospital, que não está localizado dentro da ilha e se encontra distante $15 \mathrm{Km}$ da Praia, situado no centro do município. Na cidade, existem nove postos de saúde.

A principal atividade econômica da região é o turismo, ainda que seja pouco desenvolvido e potencializado. Para a comunidade local, as principais atividades geradoras de renda são o turismo, a pesca e o comércio. Dentro da comunidade, há uma trilha para turistas; porém, não existem outros atrativos ou produtos ofertados para os turistas que visitam o espaço.

De acordo com a entrevista, para fomento à identidade cultural, existe um festival na comunidade, nomeado por "Comidinha de Praia" (realizada em setembro de cada ano), com status de atributo cultural, mas que precisa ser masi bem planejado e anunciado para atrair turistas. A comunidade local possui assistência apenas de instituições públicas, como a SETUR, SEMMA, SPU e Secretaria de Estado de Desenvolvimento Urbano e Obras Públicas (SEDOP), que nos últimos anos planeja criar uma Unidade de Conservação no Atalaia. 
Segundo a Presidente da Associação dos Barraqueiros há carência de infraestrutura no local, destacando-se a necessidade de mobilização para melhoria nas áreas de saneamento básico, transporte público e desenvolvimento à educação ambiental.

Para os proprietários de barracas da praia do Atalaia, a renda no período de alta temporada (verão) chega ao dobro do que normalmente arrecadam em época de baixa temporada (inverno). Este valor, que em meses de baixa temporada chega a $R \$ 3.000,00$, nos meses de alta temporada é de $R \$ 6.000,00$ por final de semana. Reforçou-se, no entanto, que este lucro gerado ainda é baixo e que as expectativas dos comerciantes são resultados piores, em médio prazo, pois temem perder mercado para restaurantes e grandes redes comerciais que se instalam cada vez mais próximos da praia.

A entrevistada afirmou que o desenvolvimento do turismo poderia melhorar a situação da comunidade, visto que assim haveria mais organização e limpeza, o que implicaria propriamente melhoria da qualidade de vida das pessoas que habitam a Ilha do Atalaia. A renda média das pessoas da comunidade é de cerca de um salário mínimo, advindo em boa parte do Programa "Bolsa Família".

\section{Determinação do Perfil do Turista}

Conforme os resultados obtidos, $48 \%$ dos entrevistados pertencem ao gênero masculino e $52 \%$ ao gênero feminino. A média total de idades é de 36,5 anos, o que demonstra maior independência econômica, pois fazem parte da População Economicamente Ativa (PEA), segundo dados do Instituto Brasileiro de Geografia e Estatística (IBGE, 2012). Aproximadamente $49 \%$ dos entrevistados possuem escolaridade acima do Ensino Médio; 78,22\% deles apresentam renda superior a um salário mínimo, que na época da pesquisa era de $\mathrm{R} \$ 880,00$.

Constatou-se que $65 \%$ dos turistas se locomovem até a praia por meio de carros próprios. Em contrapartida, 32\% 
chegam ao local de ônibus. Os 3\% restantes se deslocam por meio de outros meios de transportes alternativos. Isto reforça o crescente aumento do número de veículos estacionados próximo ao limite da zona costeira da Praia do Atalaia nos últimos anos. Speybroeck et al. (2006) propõem que o uso de equipamentos, dentre eles o tráfego de veículos sobre a areia da praia, podem gerar perturbações diretas na fauna e na flora, pois provocam a compactação do solo pelos pneus. Portanto, o desconhecimento dos visitantes que usufruem dessa forma de transporte acerca das consequências de seu uso indevido permeia o avanço do grau de impacto ao ecossistema costeiro.

Em relação à percepção da avaliação da praia, os aspectos considerados foram odor, limpeza, paisagem natural e ruído. Constatou-se que $76 \%$ dos visitantes classificaram como "bom" para o primeiro, 52\% como "ruim" e "péssimo" para o segundo, $66 \%$ como "ótimo" para o terceiro e $48 \%$ como "bom" para o último. No entanto, quando foram questionados acerca dos impactos causados por si mesmos no ambiente, $66 \%$ declararam não causarem impactos na área. A partir disso, percebe-se a contradição inerente entre o pensamento exposto e o discurso atribuído à pesquisa, pois, ao afirmarem não causar impactos na praia, mais da metade das pessoas entrevistadas reconheceram que há algum tipo de poluição evidente que prejudica o meio ambiente; todavia, não atribuíam para si a responsabilidade por eles.

Quando perguntados se estariam dispostos a pagar por uma atividade recreacional referente a passeios utilizando transporte alternativo para locais próximos, $89 \%$ dos turistas se declararam dispostos. Quando interrogados sobre o preço para realização desta prática, a média foi de $\mathrm{R} \$ 44,74$ por visitante. Ao ser calculado o total para essa amostra de estudo, verificou-se que seria produzido aproximadamente $\mathrm{R} \$$ 8.948,00 de renda para o local no decorrer do mês de Julho.

Portanto, como demonstrado na Tabela 2, ao ser executada uma projeção para $30 \%, 50 \%, 70 \%$ e $89 \%$ sobre o 
total de turistas que visitam o município durante o mês de julho, que seria cerca de 300.000, de acordo com a Secretaria Municipal de Meio Ambiente de Salinópolis (2016), a quantidade de pagantes seria 90.000, 150.000, 210.000 e 267.000, respectivamente. Assim, a renda gerada ao local por temporada aumentaria, conforme esse total de visitantes dispostos a pagar, para: $\mathrm{R} \$ 4.026 .600,00 ; \mathrm{R} \$ 6.711 .000,00$; $\mathrm{R} \$$ 9.395.400,00 e $\mathrm{R} \$ 11.945 .580,00$. A partir disso, o incentivo a atividades recreativas de qualidade pode estimular o desenvolvimento local das comunidades próximas, pois poderia haver a inserção dos moradores.

\section{Tabela 2 - Projeção do aumento da renda de acordo com a disposição a pagar pelo turista}

\begin{tabular}{cc}
\hline No de turistas disposto a pagar pelo passeio & $\begin{array}{c}\text { Renda gerada durante o mês de Julho } \\
\text { pela disposição a pagar pelo passeio }\end{array}$ \\
\hline 1 & $\mathrm{R} \$ 44,74$ \\
200 & $\mathrm{R} \$ 8.948,00$ \\
90000 & $\mathrm{R} \$ 4.026 .600,00$ \\
150000 & $\mathrm{R} \$ 6.711 .000,00$ \\
210000 & $\mathrm{R} \$ 9.395 .400,00$ \\
267000 & $\mathrm{R} \$ 11.945 .580,00$ \\
\hline
\end{tabular}

Fonte: Autores (2016).

Logo, segundo a Tabela 2, torna-se evidente o potencial de geração de renda à comunidade do entorno e município por meio do pagamento de cada passeio, criando-se novos empregos para os moradores que podem ser qualificados para se tornarem guia de turismo e auxiliarem os visitantes durante a atividade.

O conhecimento sobre o perfil do turista é importante para análise da Capacidade de Carga Turística (CCT), pois, por meio de sua percepção, podem ser observadas algumas características que também motivam o crescimento dos impactos gerados sobre os recursos naturais e as atividades praticadas desejadas por estes visitantes. Assim, a compreensão sobre o comportamento das pessoas que geralmente 
frequentam a Praia do Atalaia é fundamental para determinar o tipo de turismo predominante na área.

\section{Determinação de Indicadores de Capacidade de Carga Turística (CCT)}

Para o cálculo da Capacidade de Carga Física (CCF) a partir do método de Cifuentes (1992), foi necessário o conhecimento dos valores da área total da superfície de estudo $\left(\mathrm{m}^{2}\right)$, área ocupada por pessoa, o tempo que a área está aberta e o tempo para a visitação ao local. De acordo com o valor adquirido por meio do programa Google Earth Pro, a faixa de areia da Praia do Atalaia, onde o estudo foi realizado, apresenta aproximadamente $406.537 \mathrm{~m}^{2}$.

Em relação à variável tempo, tanto o total de abertura do local quanto de visitação, não foi considerado na pesquisa, porque como se trata de um ambiente de praia não se tem o controle da duração de permanência durante o dia e também o ingresso dos visitantes. Geralmente, esse fator é aplicado para trilhas ou outros atrativos, em que é preciso a formação de pequenos grupos de pessoas com roteiro para a visitação (RUSCHMANN; PAOLUCCI; MACIEL, 2008).

Segundo a adaptação do método de Cifuentes por Ruschmann et al. (2008), a área ocupada por pessoa em ambientes de praia foi dada como $10 \mathrm{~m}^{2}$. Portanto, para a praia do Atalaia, em Salinópolis, foram utilizados os dados a seguir:

- Área total do local (S): $406.537 \mathrm{~m}^{2}$

- Área ocupada por pessoa (SP): $10 \mathrm{~m}^{2}$

Assim, com a utilização da equação simplificada, ou seja, sem a consideração do fator tempo, tem-se:

$$
\mathrm{CCF}=\frac{406.537 \mathrm{~m}^{2}}{10 \mathrm{~m}^{2}}
$$

Após a efetivação dos cálculos, a capacidade de carga física da Praia do Atalaia foi estimada em 40.654 usuários. Porém, para Arangunen et al. (2008), esse indicador não deve 
ser considerado como definitivo para planejamento e gestão de praias, uma vez que a simples existência de espaço não é fator preponderante ao desenvolvimento da indústria do turismo e, portanto, devem ser equacionados outros aspectos que apropriam o exercício das atividades de veraneio, como os parâmetros da infraestrutura básica.

Para a determinação da Capacidade de Carga Real (CCR), primeiramente se estimou o valor do fator de correção. Neste estudo, dois fatores foram mensurados: precipitação (FC1) e brilho solar (FC2). O período de chuvas no município de Salinópolis deve ser considerado como fator de restrição à presença de turistas na praia. Desse modo, para ser encontrado esse fator, usufrui-se do período mais chuvoso durante o ano (janeiro a junho), ou seja, 182 dias anualmente.

O brilho solar também é um importante fator que pode influenciar a ida de turistas à praia. Em Salinópolis, o total do brilho durante o ano é 2.242 horas, e os meses de julho a outubro são os que mais contribuem com essa quantidade. Na Tabela 3, observam-se os resultados dos fatores de correção:

Tabela 3 - Fatores de Correção para a Capacidade de Carga Real (CCR) da Praia do Atalaia

\begin{tabular}{cccc}
\hline Fatores de Restrição & $\begin{array}{c}\text { Magnitude Limitante } \\
\text { (ML) }\end{array}$ & $\begin{array}{c}\text { Magnitude Total } \\
\text { (MT) }\end{array}$ & $\begin{array}{c}\text { Fator de Correção FC= 1- } \\
\text { (ML/MT) }\end{array}$ \\
\hline Precipitação & 182 dias/ano & 365 dias & 0,4986 \\
Brilho Solar & 2242 horas/ano & 8760 horas & 0,7441 \\
\hline
\end{tabular}

Fonte: Autores (2016).

Então, a partir dos valores adquiridos dos fatores de correção, calcula-se a Capacidade de Carga Real (CCR) de acordo com a equação 4 :

$\mathrm{CCR}=40,654 \times(0,4986 \times 0,7441)=15083$ usuários $/ \mathrm{dia}$

Ao que concerne a determinação da Capacidade de Carga Efetiva (CCE) da Praia do Atalaia, primeiramente 
é preciso realizar a análise da capacidade de manejo ou de gestão da área. Dessa maneira, considerando que a praia é o local que recebe a maior quantidade de turistas, sobretudo durante o período de alta temporada (férias), transformase em área prioritária para os investimentos turísticos com equipamentos e infraestrutura adequados para o recebimento e satisfação do turista.

No entanto, ao ser feita a avaliação dos indicadores, como sanitários e banheiros públicos; serviços de bares e restaurantes; locais para estacionamento, entre outros, definidos para a verificação da qualidade de gestão da área, percebeu-se a insuficiência em relação ao nível de infraestrutura quando comparado ao adequado para o grau de atratividade da área, para o satisfatório desenvolvimento do turismo. Em vista disso, com base em pesquisa por meio de observação in loco, definiu-se que a capacidade de manejo da área é de 60\%, como exposto na Tabela 4.

Tabela 4 - Descrição dos valores atribuídos aos indicadores de manejo da Praia do Atalaia

\begin{tabular}{lccccc}
\hline Indicador & $\begin{array}{c}\text { Valor } \\
\text { Atribuído }\end{array}$ & $\begin{array}{c}\text { Valor } \\
\text { Ótimo }\end{array}$ & $\begin{array}{c}\text { Percentagem } \\
\text { Válida }\end{array}$ & Descrição & $\begin{array}{c}\text { Grau de } \\
\text { Atratividade }\end{array}$ \\
\hline Sanitários e banheiros públicos & 2 & 3 & 66.7 & Poucos & Médio \\
$\begin{array}{l}\text { Serviços de bares e restaurantes } \\
\text { Locais para estacionamento }\end{array}$ & 3 & 3 & 100 & Adequado & Alta \\
$\begin{array}{l}\text { Facilidade para informação } \\
\text { (guia de turismo) }\end{array}$ & 2 & 3 & 66.7 & Poucos & Médio \\
$\begin{array}{l}\text { Transporte público para a praia } \\
\text { Acessibilidade à praia }\end{array}$ & 2 & 3 & 33.3 & Ausentes & Baixo \\
$\begin{array}{l}\text { Elementos e infraestruturas de } \\
\text { salva-vidas }\end{array}$ & 2 & 3 & 66.7 & Poucos & Médio \\
$\begin{array}{l}\text { Limpeza na praia (resíduos) } \\
\text { Saneamento básico (esgotos e }\end{array}$ & 2 & 3 & 66.7 & Poucos & Médio \\
distribuição de água) & 1 & 3 & 66.7 & Poucos & Médio \\
Locais para recreação & 1 & 3 & 33.3 & Ausentes & Baixo \\
\hline$\sum$ e $\mu$ & $\mathbf{1 8}$ & $\mathbf{3 0}$ & $\mathbf{6 0}$ & & Ausentes \\
\hline
\end{tabular}

Fonte: Autores (2016). 
Nota-se que por meio de checklist e análise dos questionários de percepção qualitativa e quantitativa do turista, $76 \%$ das pessoas entrevistadas consideram como "bom" o atendimento em bares e restaurantes, o que ressalta como adequado o valor atribuído na Tabela 4. De acordo com $6 \%$ dos entrevistados, deveria haver orlas para carros, o que indica que $94 \%$ deles não se preocupam com a presença de automóveis na faixa de areia; isto fortalece a informação de que existem poucos locais para estacionamento.

Em relaçãoà presença de guia de turismo que contribuam para disseminar informações acerca dos aspectos naturais, culturais e históricos do local, $74 \%$ das pessoas acreditam na sua indispensabilidade; destes, $60 \%$ explanam que prefeririam que o guia fosse um representante da comunidade local e não uma pessoa oriunda de agências de turismo. Isto beneficiaria todos os atores sociais, pois geraria renda e desenvolvimento para a comunidade e também para o próprio município.

Para 47\% dos entrevistados, há necessidade de melhoria de serviços de limpeza na praia, o que reflete na avaliação da capacidade de manejo, porque é uma das variáveis determinantes de infraestrutura para satisfazer os visitantes. A ausência de locais para recreação gera o resultado de 94\% dos entrevistados afirmarem que gostariam de participar de atividades esportivas e ambientais, como caminhadas, aeróbicas, trilhas, dentre outros. No entanto, em uma parte distante da praia há espaço para desenvolvimento e potencialização do turismo sustentável, pois praticantes de esportes levam seus equipamentos, de acordo com a Figura 3. 
Figura 3 - Pessoa praticando esporte na Praia do Atalaia

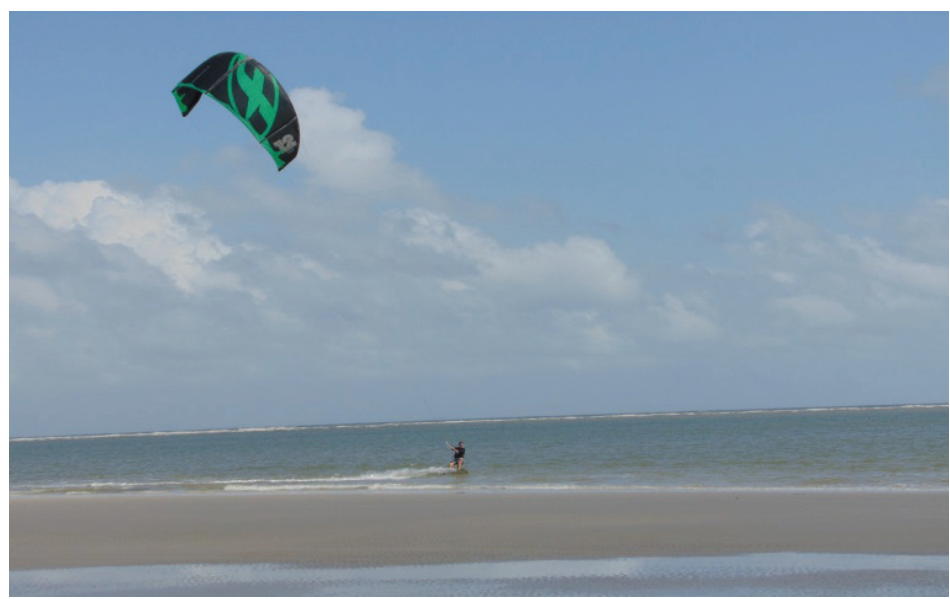

Fonte: Autores (2016).

Com a estimativa da capacidade de manejo pode ser calculada a Capacidade de Carga Efetiva (CCE) suportada pela Praia do Atalaia, utilizando-se a equação 5. Assim:

$$
\mathrm{CCE}=9049,8 \text { usuários/dia }
$$

Os indicadores de Capacidade de Carga Turística (CCT) determinados nesse estudo foram resumidos na Tabela 5. Contudo, a determinação do número máximo de turistas que podem frequentar a praia não é considerada como a única forma de efetivar a gestão de certa área, pois estes valores devem ser analisados como base para o desenvolvimento da infraestrutura adequada, visando também aos impactos ocasionados pelos visitantes.

Tabela 5 - Resumo da Capacidade de Carga Turística da Praia do Atalaia

\begin{tabular}{|c|c|}
\hline Níveis de Capacidade & Considerando $10 \mathrm{~m}^{2} / \mathrm{usuário}$ \\
\hline Capacidade de Carga Física & 40.654 usuários/dia \\
\hline Capacidade de Carga Real & 15.083 usuários/dia \\
\hline Capacidade de Carga Efetiva & $9.049,8$ usuários/dia \\
\hline
\end{tabular}

Fonte: Autores (2016). 
Diante do exposto, segundo Sousa, Pereira e Gimenez. (2016), a capacidade de carga é uma ferramenta essencial para a gestão de áreas costeiras visando a melhorar o seu potencial. Porém, a análise de variáveis relacionadas à qualidade da visita e à preservação dos recursos é de extrema importância para auxiliar no aperfeiçoamento dos indicadores. Assim, a avaliação da CCT é uma medida necessária para servir como base para o manejo dessas áreas.

\section{Considerações finais}

A atividade turística de Salinópolis tem potencial para promover o aumento do emprego, o que contribuiria para elevar a renda das famílias locais envolvidas direta e/ou indiretamente na economia do turismo, principalmente, por meio de atividades alternativas como formação e qualificação de guia turísticos, venda de passeios de barcos e jangadas, exploração de áreas naturais.

Esta pesquisa, portanto, contribui com a construção de dados e informações sociais, econômicas e ambientais, até então, pouco conhecidas sobre os turistas que usam a praia do Atalaia e, sobretudo, em relação aos aspectos de infraestrutura física (bares, restaurantes e hotéis) e natural obtidas por meio da determinação e análise da capacidade de carga.

Os indicadores de capacidade de carga turística são úteis para a elaboração de planos, projetos e ações de redução de impacto e de regulação de uso recreativo da praia e podem, por isso, subsidiar políticas públicas locais que objetivem manter as condições naturais que ainda resistem às ações do homem em benefício das gerações futuras.

\section{Referências}

ARANGUNEN, Jesús; MONCADA, José Alí; NAVEDA, Jorge; RIVAS, David; LUGO, Carlos. Evaluación de la capacidad de carga turística en la playa Conomita, Municipio Guanta, Estado Anzoátegui. Revista de Investigación, Caracas, v. 32, n. 64, p. 31-61, Caracas, 2008. 
BRASIL. Lei no 11.771, de 17 de setembro de 2008. Define as atribuições do Governo Federal no planejamento, desenvolvimento e estímulo ao setor turístico; revoga a Lei $\mathrm{n}^{\circ}$ 6.505, de 13 de dezembro de 1977, o Decreto-Lei no 2.294, de 21 de novembro de 1986, e dispositivos da Lei no 8.181, de 28 de março de 1991; e dá outras providências. Disponível em: <http://www.planalto.gov. br/ccivil_03/_ato2007-2010/2008/lei/111771.htm >. Acesso em: 27 ago. 2016.

BRASIL. Ministério das Relações Exteriores. Turismo no Brasil 2007-2010. 2006. Disponível em: <http://www.sisbin.ufop.br/ novoportal/wp-content/uploads/2015/03/MISTERIO-DASRELACOES-turismo-no-brasil.pdf>. Acesso em: 27 ago. 2016.

CIFUENTES, Miguel Cifuentes. Determinación de Capacidad de Carga Turística em áreas protegidas. Centro Agronômico Tropical de Investigación y Enseñanza - CATIE, Tirrialba, Costa Rica, 1992.

; MESQUITA, Carlos Alberto B.; MÉNDEZ, Jasmina; MORALES, María Eugenia; AGUILAR, Naikoa; CANCINO, Delmar; GALLO, Melibe; JOLÓN, Jolón; RAMÍREZ, Carla; RIBEIRO, Natasha; SANDOVAL, Eduardo; TURCIOS, Mónica. Capacidad de carga turística de las áreas de Uso Público del Monumento Nacional Guayabo, Costa Rica. Costa Rica: WWF Centro America, 1999.

CORDEIRO, Itamar; LEITE, Nathália Körössy; SELVA, Vanice. Determinação da capacidade de carga turística a partir do método Cifuentes et al. (1992): Aplicação à Praia dos Carneiros (Tamandaré/ PE). Revista Turismo Visão e Ação (Online), v. 15, p. 57-70, 2013.

CORRÊA, Maria Laetitia; PIMENTA, Solange Maria; ARNDT, Jorge Renato Lacerda. Turismo, sustentabilidade e meio ambiente: contradições e convergências. Belo Horizonte: Autêntica Editora, 2009.

FACULDADE DE CIÊNCIAS DA UNIVERSIDADE DE LISBOA (FCUL). Caracterização da capacidade de ocupação de praias. Lisboa, 2013.

FIRMINO, Fabiana dos Santos. Dinâmica do turismo na zona costeira nordestina: Questões conflitantes do desenvolvimento turístico da Praia dos Carneiros (Tamandaré/PE). 2006. 201 f. Dissertação (Mestrado em Gestão e Políticas Ambientais) Programa de Pós-Graduação em Gestão e Políticas Ambientais, Universidade Federal de Pernambuco, Recife, 2006. 
GOOGLE EARTH. Satélite Cnes/Spot Image, 2016.

INSTITUTO BRASILEIRO DE GEOGRAFIA E ESTATÍSTICA. Indicadores IBGE: Principais destaques da evolução do mercado de trabalho nas regiões metropolitanas abrangidas pela pesquisa 2003-2012. Disponível em: <http://www. ibge.gov.br/home/estatistica/indicadores/trabalhoerendimento/ pme_nova/retrospectiva2003_2012.pdf>. Acesso em: 21 nov. 2016.

KIRSTEN, José Tiacci. Análise estatística. In: WHITE, Oriana Monarca; HERLINGER, Maximiliano; PERDIGÃO, Dulce Mantellae (Org.). Teoria e prática da pesquisa aplicada. Rio de Janeiro: Elsevier Editora Ltda, 2011.

MANKIW, N. Gregory. Introdução à Economia. São Paulo: Cengage Learning, 2009.

MITRAUD, Sylvia. Monitoramento e controle de impactos de visitação. In: . (Org.). Manual de ecoturismo de base comunitária: ferramentas para um planejamento responsável. Brasília:WWF Brasil, 2003. p. 315-362.

NUNES, I. Turismo, desenvolvimento e dependência em Cabo Verde. 2009. 126 f. Dissertação (Mestrado em Economia) Faculdade de Economia, Universidade de Coimbra, Coimbra, 2009.

ORGANIZACIÓN MUNDIAL DEL TURISMO. Código Ético Mundial para el Turismo. 2001. Disponível em: <http:// cf.cdn.unwto.org/sites/all/files/docpdf/gcetbrochureglobalcodees. pdf $>$. Acesso em: 28 ago. 2016.

ORGANIZAÇÃO MUNDIAL DO TURISMO. Introdução à metodologia da pesquisa em turismo. São Paulo: Roca, 2006.

PORTUGUEZ, Anderson Pereira; SEABRA, Giovanni de Farias; QUEIROZ, Odaléia Telles M. M. Turismo, espaço e estratégias de desenvolvimento local. 2012. 396 f. Grupo de Estudos e Pesquisa em turismo, espaço e estratégias de desenvolvimento local - GEPTEEDL, Universidade Federal da Paraíba,João Pessoa, 2012.

ROCHA, Jefferson Marçal da. Desenvolvimento e sustentabilidade do turismo: preceitos da teoria da capacidade de carga turística. Rosa dos Ventos - Turismo e Hospitalidade, v. 3, n. 3, p. 382-392, set./dez. 2011.

RUSCHMANN, Dóris V. De M. Turismo e planejamento sustentável: a proteção do meio ambiente. São Paulo: Papirus, 2008. 

Habitacional Canto da Brava. Revista Brasileira de Pesquisa em Turismo, v. 2, n. 2, p. 41-63, jul. 2008.

SALINÓPOLIS. Secretaria Municipal de Meio de Ambiente de Salinópolis. Salinópolis, 2015.

SANTOS, Glauber Eduardo de Oliveira; KADOTA, Décio Katsushigue. Economia do Turismo. São Paulo: Ed. Aleph, 2012.

SILVA, Iracema Reimão; BITTENCOURT, Abílio Carlos da Silva Pinto; DIAS, J. A; SOUZA FILHO, José Rodrigues de. Qualidade recreacional e capacidade de carga das praias do litoral norte do estado da Bahia, Brasil. Revista de Gestão Costeira Integrada, v. 2, n. 2, p. 131-146, 2012.

SILVA, Iracely Rodrigues da; PEREIRA, Luci Cajueiro Carneiro; TRINDADE, Wellington Nascimento; MAGALHÃES, André; COSTA, Rauquírio Marinho da. Natural and anthropogenic processes on the recreational activities in urban Amazon beaches. Ocean \& Coastal Management, v. 76, p. 75-84, 2013.

SILVA, Susana Alexandra Ferreira da. Gestão de praias da Costa de Caparica. A capacidade de carga, o valor da onda, a segurança e informação. 2012. 177 f. Dissertação (Mestrado em Engenharia do Ambiente) - Universidade de Nova Lisboa, Nova Lisboa, 2012.

SOUSA, Luiz Gonzaga de. Potencialidades Locais, Turismo e Desenvolvimento Local Cariri Paraibano. 2011. 132 f. Tese (Doutorado em Sociedade e Recursos Naturais) - Programa de Pós-Graduação em Sociedade e Recursos Naturais, Universidade Federal de Campina Grande, Campina Grande, 2011.

SOUSA, Rosigleyse C. de; PEREIRA, Luci C.C.; JIMENEZ, José A. Management of estuarine beaches on the Amazon coast though the application of recreational carrying capacity índices. Journal of Coastal Research: Special Issue 75 - Proceedings of the 14th International Coastal Symposium, Sydney, v. 59, p. 216-225, mar. 2016.

SPEYBROECK, Jeroen; BONTE, Dries; COURTENS, Wouter; GHESKIERE, Tom; GROOTAERT, Patrick; MAELFAIT, Jean- Pierre; MATHYS, Mieke; PROVOOST, Sam SABBE, Koen; STEINEN, Eric W. M; VAN LANCKER, Vera; VINCX; Magda; DEGRAER, Steven Beach Nourisment: An ecologically 
sound coastal defence alternative? A review. Aquatic conservation: Marine and Freshwater ecosystems, v. 16, p. 419-435, 2006.

TEIXEIRA, Paulo Roberto; OLIVEIRA, Lillian Tavares. O Método de Cifuentes e a Avaliação da Capacidade de Carga na Trilha na "Serrinha". São João da Baliza, Roraima. Revista Rosa dos Ventos - Turismo e Hospitalidade, v. 7, n. 1, p. 120-132, jan./ mar. 2015.

TELES, Reinaldo Miranda de Sá. A importância do território na prática do planejamento turístico - reflexões acerca do Brasil. In: RUSCHMANN, Doris van de Meene; SOLHA, Karina Toledo (Org.). Planejamento Turístico. Barueri: Manole, 2006. p. 45-65.

ZAMBONI, Nadia Selene; PÉREZ, Carlos Daniel. Análise da Capacidade de Carga Turística como ferramenta para a gestão sustentável do turismo nos ambientes recifais da praia de Porto de Galinhas, Ipojuca/PE. In: CONGRESSO BRASILEIRO DE GESTÃO AMBIENTAL, 4., 25-28 nov. 2013, Salvador. Anais... Salvador: Instituto Brasileiro de Estudos Ambientais e Saneamento, 2013. p. 1-3.

Recebido em: 25/07/2017

Aceito em: 03/12/2017 
124 Revista Grifos

\title{
TOURISM AS A POTENTIAL FOR PROMOTING SUSTAINABLE LOCAL DEVELOPMENT IN THE ATALAIA, IN SALINÓPOLIS - PA
}

\begin{abstract}
Tourism has been consolidating as an important income generating activity for a city, mainly coastal municipalities (such as Salinópolis), which became an essential to the tourist environment in the State of Pará. The objective of this research was to identify and analyze the determinants of natural characteristics and infrastructure logistics for the promotion of tourism in the beach of Atalaia, in Salinópolis. The calculation of Tourist Carrying Capacity indicators was made using the method Cifuentes (1992), which is constituted by Physical Carrying Capacity (PCC), Real Carrying Capacity (RCC) and Effective Carrying Capacity (ECC). Thus, the determination of the profile of the tourist that frequents the beach was obtained, and the maximum capacity of visitors approached 9049 users/ day, considering vacations. The knowledge of this value becomes a fundamental instrument to assist the management of the area and to encourage quality tourist activity with adequate infrastructure in this region.
\end{abstract}

Keywords: Local Community. Atalaia Beach. Tourist Carrying Capacity. Tourism. 